\title{
Understanding the Cloud Computing: A Review
}

\author{
Kamalinder Kaur \\ Assistant Professor \\ Dept. of Computer Science \& Engineering \\ Chandigarh Engineering College, Landran \\ Punjab, India.
}

\author{
Nupur \\ Assistant Professor \\ Dept. of Computer Science \& Engineering \\ Chandigarh Engineering College, Landran \\ Punjab, India.
}

\begin{abstract}
Now a days the work is being done by hiring the space and resources from the cloud providers in order to do work effectively and less costly. This paper describes the cloud, its challenges, evolution, attacks along with the approaches required to handle data on cloud. The practice of using a network of remote servers hosted on the Internet to store, manage, and process data, rather than a local server or a personal computer. The need of this review paper is to provide the awareness of the current emerging technology which saves the cost of users.
\end{abstract}

Keywords_cloud; SAAS; providers; SOA; resources.

\section{INTRODUCTION}

The term "cloud" deals with the group of system which exchanges the data from one system to another by providing resources over the internet. The resources existing in cloud can be used enormously by user whenever they need it. In cloud computing, physical infrastructure is usually desired to third party provider for service of internet instead of setting up their own resources by the customers. Customers use the resources as a service and pay only for the used quantity of resources. Cloud providers use self-service abilities and virtualization technologies for allocating resources via network infrastructure. In cloud environment, many kinds of virtual machines are put on the same physical server for communications. In cloud, customers are paid for what they used and are not paid for storage or infrastructure considered as local resources.

\section{LITERATURE SURVEY}

"Evolution of Cloud Computing, its Approaches and Comparison with Grid Computing" Rajleen Kaur, Amanpreet Kaur. In this review paper they have discussed about the cloud computing characteristics and its evolution. As in this the cloud computing and its approaches are studied, the cloud computing will increase in today's scenario. So, the cloud computing have a great impact on society. Review paper on Cloud Computing, Seema Sharma, Jyoti Godara. In this paper they discuss about various deployment model and cloud services of cloud computing. Cloud computing is recent buzzword in IT world. The Leader in the companies, such as Microsoft, Amazon, IBM, and Google provided their initiative in promoting cloud computing. But still there are some issues in the cloud computing like testing issues, security issues, and privacy issues.

Research Agenda in Cloud Technologies. Ilango Sriram, Ali Khajeh-Hosseini. This paper has presented the work published by the academic community advancing the technology of cloud computing. Much of the work has focused on creating standards and allowing interoperability, and describes ways of designing and building clouds.

\section{Kinds Of ClOUd COMPUTING}

\section{A. Public Cloud}

Standard models providers to create many resources such as applications and storage, which are available to the public. Public cloud services are either free or not. Public clouds which are running applications outwardly by large service providers, provides some benefits over private clouds.

\section{B. Private Cloud}

It identifies to internal services of a business that is not accessible for regular people. Private cloud is a promoting term for a structural design that provides hosted services abaft the firewall to the people.

\section{Hybrid Cloud}

A domain that company offers and controls some resources internally and has some others for public consumption. It is a group of private and public clouds. Cloud provider, has a service that uses private cloud and is only authorized by certified staff and is protected by firewalls from outside accessing. Also using a public cloud environment in which external users can access to it. In cloud computing, the capacity is lifted so that workload can be reduced. For successively working applications, the local computers do not to take the heavy load. Actually this burden is handled by group of computer which forms the cloud. On Customer side the demand of hardware and software reduces. So, the thing 
which is needed to be considered for software on computer is the web browsers, like Google chrome, opera, Mozilla Firefox etc. Structures of cloud computing consists of on-demand selfservices, broad network area, measure services, rapid elasticity, reduced pooling, multi-tenacity and sharing of infrastructure. The Cloud computing requires Software, hardware, application stage, arrangement and storage with an internet connection.

\section{Methodologies Of Cloud Computing}

\section{A. SaaS-Software as a Service}

\section{B. PaaS-Platform as a Service}

\section{IaaS-Infrastructure as a Service}

Public customers have voluntarily included cloud computing facility like Google-email, Facebook, YouTube, yahoo, Hotmail, Twitter etc. It provides decline in management duties and the main focus is on innovation and production. It is widely used in business which meets the requisite of varying environment. Many firms provide services from the cloud like Yahoo, Google, Microsoft, SalesForce.com, Amazon etc.

\section{Growth Of Cloud Computing}

There is an involvement of research in defining the cloud computing and Youssef et al. were first among the persons to give knowledge of cloud computing concept along with its modules. According to the researchers it is an arrangement of concepts in research fields like SOA, grid computing, virtualization, distributed computing. Conferring to Youseff, "cloud computing is stated as a new computing archetypal that allows users to temporarily employ computing infrastructure over the network, restored as a service by the cloud-provider at feasibly one or more levels of abstraction" (Youseff et al. 2008). Conferring to Armbrust et al. "Cloud Computing refers to both the applications carried as services over the Internet and the hardware and systems software in the data centers that offer those services. The services themselves have long been denoted as Software as a Service (SaaS). It's the data center hardware and software is what we say a Cloud. When a Cloud is made available in a pay-as-you-go mode to the general public, is called as a Public Cloud, the facility being sold is Utility Computing. We use the term Private Cloud to refer to internal datacenters of a business or other organization, not obtainable to the general public. Therefore, Cloud Computing is the totality of SaaS and Utility Computing, but does not include Private Clouds"

\section{FEATURES}

As per the meaning of the cloud computing there are generally five essential characteristics of the clouds. It is understandable that missing any of these characteristics is not considerable in it.

\section{A. On Demand Capabilities}

In business, cloud computing provider will secure the cloud computing services, it considered as a software vendor. The user can access services and can change them through online control panel without interacting with the server or it can be done straight with the provider.

\section{B. Wide Network Access}

Now a day, all digital devices like tablet, mobiles, laptops, etc. can access broad networks whenever they come in connect with a simple network access point. In business, this feature is very valuable because employees can stay connected with contracts, proposals, projects and customers during office hours even off times.

\section{Resources Pooling}

In the cloud computing environment, the employee can share the data or services simultaneously from any location at any time within business management software hosted at the cloud.

\section{Rapid Elasticity}

Cloud computing also offers the flexibility and scalability up to that extent that you can add or remove the users and services as per your need.

\section{E. Measured Service}

The cloud computing is so affordable that you can access services and for what type of service you used you have to pay for it. It can be examined from both the sides including source's side and user's side and hence improves transparency.

\section{CHARACTERISTICS}

Infrastructure Sharing is where the user shares the infrastructure on a virtualized concept, allowing the sharing of physical utilities, storage, networking proficiencies.

\section{A. Self-motivated Provisioning}

It allows services on the basis of requirement of present demands. It can be done automatically using automation, allowing the enlargement and reduction of service proficiency. The self- motivating scaling is required to be done by maintaining the great levels of reliability and security.

\section{B. Access of Network}

It requires to be called up across the internet from a variety of devices such as desktops, laptops, palmtops, tablets, mobile devices, using standards-based APIs (such as HTTP). Setting out of services in the cloud consists of everything from using business applications to the latest applications on smartphones.

\section{Metering Management}

It is helpful in order to generate the reports and create the bills for the reading, the users has used the resources during that period of assignment. It gives optimized service. They have really used during the billing period. 
In essence, cloud computing allows the desirable work doing from any place any time any location for which the user has to pay about the actual usage.

\section{SERVICE MODELS}

The following are the models which are required after the cloud is being deployed.

\section{A. Saas - Software As A Service}

Consumer is the payee on the amount he accesses and uses a request and facility provided by the cloud. For example Google apps, is a source in which information is shared and interacted between the customer and provider. Also the contribution of Microsoft is remarkable in this area, and as part of the cloud computing option for Microsoft ${ }^{\circledR}$ Office 2010, through its cloud-based Online Services, its Applications are obtainable to those customers having Office volume licensing and Office Web Applications subscriptions.

\section{B. Paas - Platform As A Service}

To install software and applications in the cloud, customers purchase access to the platforms. Consumers do not manage operating systems and network accesses, and there might be restrictions as to which applications can be deployed.

\section{Iaas - Infrastructure As A Service}

Customers do not control the cloud infrastructure, but can perform controlling and monitoring of the systems in terms of operating systems, application software, storage, and network connections.

Another subset known as CaaS-Communication as a Service. It is a meant for hosted IP telephony services. In this context, CaaS may be viewed as a subset of SaaS- Software as a Service (SaaS) - End user application is delivered as a service. There is an abstraction of platform and infrastructure and less effort is required to deploy CaaS.

Platform as a Service (PaaS) - Custom applications and services can be deployed through this application platform inexpensive application can be built and deployed easily, though managed services are needed.

Infrastructure as a Service (IaaS) - The cost and necessity for dedicated systems is minimized as physical infrastructure is abstracted to deliver computing, storage, and networking as a service.

\section{BENEFITS}

\section{A. Cost Savings}

To get a hike in computing capabilities, companies can lessen their capital expenditures and use operational ones. It requires less in-house information technology resources to provide system support for the growth of company.

\section{B. Scalability/Flexibility}

Companies can start their setup from scale to large .In order to fulfill the consumer demand, companies can use extra resources if required because of scalability feature provided by cloud computing.

C. Reliability

It supports disaster management facility and provides consistency in business.

\section{Maintenance}

In order to avoid application installations onto PCs, system maintenance is performed by cloud service providers and through Application Program Interface, the services are accessed which helps in reducing maintenance cost.

\section{E. Mobile Accessible}

Productivity of mobile workers has been increased due to availability of resources from any corner of the world.

\section{Cloud Computing Issues}

\section{A. Technical Issues}

Cloud computing needs high technology and strong internet connection. Through this technology we can access the data and information anywhere and anytime. As we know technology is always prone to some technical issues. Therefore high maintenance and good internet connection is required for using server at all the time.

\section{B. Security In The Cloud}

Before using this technology, all company's important information is shared with a group of service providers other than those directly involved in providing the services. As a result company comes under a great risk. A consistent service provider plays a vital role in securing the information.

\section{Prone To Attack}

The information stored in cloud is accessible to external hackers and threats. As the data is not completely secure on the internet. There are always some chances of hacking of sensitive data.

\section{Challenges}

The prominent challenges associated with cloud computing are described below. Although some of the following may cause a decline when adding more services in the cloud, but if handled with care and observation in planning stages, most can become an opportunity.

\section{A. Security and Privacy}

The major issues related to cloud computing that are generally due to the slowdown of deployment of cloud services includes storing and securing data, and monitoring the use of the cloud by the service providers. These can be resolved, e.g. the information is stored inside the organization, but permitting it to be accessed in the cloud. For this to occur, a Hybrid cloud could be used to support strong security mechanisms between organization and the cloud. 


\section{B. Lack of Standards}

It is unlikely that most clouds will be interoperable as no standards are associated with the standard interfaces of clouds. In order to resolve this problem, the Open Cloud Consortium is working on cloud computing standards and practices and the Open Grid Forum is developing an Open Cloud Computing Interface. The conclusions of these groups can be concerned, but it is not sure whether they will address deployment of the services. However, the services are leveraged if the modern standards are kept up to date.

\section{Continuous Evolution}

Customer needs are arising day by day, therefore the necessities for interfaces, networking, and storage of information. This shows that a public cloud, constantly emerging.

\section{Concerns regarding Compliance}

Two of many compliance concerns affecting cloud computing includes the Sarbanes-Oxley Act (SOX) in the US and Data Protection directives in the EU. These deal with the type of data and application for which the cloud is needed. For maintaining the security and secrecy, Hybrid cloud deployment is needed which comprises of one cloud storing the data internal to the organization.

\section{ATtACKS In ClOUd COMPUTING}

As the cloud can give service to legitimate users it can also provide service to users that have spiteful purpose. For achieving the objective like a DDOS attacks against cloud itself or organizing another user in the cloud, a hacker can use a cloud to host a spiteful application. Assume that an attacker, who knows that his victim is accessing specific cloud provider, can draft an attack in opposition to his offended. This states that both attacker and victim are in same network but are using virtual machines instead of physical network.

\section{A. DDOS Attack}

Distributed Denial of Service (DDOS) attacks usually focus on high number of IP packages at particular entry point. In cloud computing the resources are shared by a number of client machines. DDOS attacks may have the possibility of having much greater impact than single rented architectures. If cloud doesn't have abundant resources to provide services to its consumers then this may cause unwanted DDOS attacks, the solution for this is increase in number of such vital resources. But problem is when bot-net is used by malicious user deliberately for a DDOS attacks. Most network countermeasures cannot distinguish good traffic from bad traffic and cannot stop the cascade of traffic and therefore cannot protect against DDOS attacks. When attacks are identified and have pre-defined signatures then Intrusion Prevention Systems (IPS) becomes active but if there is legitimate content with bad intentions, IPS becomes ineffective. Unfortunately, because attacker can easily by pass firewalls, firewalls are fragile and ineffective against DDOS attacks like IPS solutions since these are designed to allow justifiable traffic and attacks produce abundant traffic from so many different hosts for cloud, its Internet connection, is unable to hold the traffic. It is prominent to say that DDOS protection works on Network Virtualization layer rather than Server Virtualization.

\section{B. Cloud Against DDOS Attack}

DDOS attacks when launched from a botnet with large numbers of automaton machines become one of the dominant threats in the world. DDOS attack sends a substantial overflow of packet to a Web server from various hosts. In this condition, the cloud may be part of the solution. It's interesting to consider that websites having limited server possessions and facing DDOS attacks are getting the benefits of using cloud that provides more resource to tolerate such attacks.

\section{DePlOyMENT MODELS}

Depending upon the needs, deploying of cloud computing can vary. The following are the four deployment models that include the properties which support the needs of the services and users of the clouds in specific ways

\section{A. Private Cloud}

The private cloud is meant for the internal working of a particular organization. The operation may be in-house or with a third party on the ground.

\section{B. Community Cloud}

The cloud resources are public among a numerous organizations having same interests and requests. Due to this, the capital expenditure costs for its establishment are reduced as the cost is shared among different organizations.

\section{Public Cloud}

The cloud service provider assigns cloud resources to the public on a commercial basis. This requires very little financial outlay, compared to the capital expenditure requirements usually associated with other deployment options, by a consumer to develop and deploy a service in the cloud.

\section{Hybrid Cloud}

This cloud infrastructure contains any number of clouds of any type, but the interfaces are required to allow data and/or applications to be transferred from one cloud to another. This can be a private and public arrangement of clouds that support the requirement to hold some data in an organization.

\section{REFERENCES}

[1] S. Arnold (2009, Jul.). "Cloud computing and the issue of privacy." KM World, pp14-22. Available: www.kmworld.com [Aug. 19, 2009].

[2] A Platform Computing Whitepaper. "Enterprise Cloud Computing: Transforming IT." Platform Computing, pp6, 2010.

[3] Global Netoptex Incorporated. "Demystifying the cloud. Important opportunities, crucial choices.” pp4- 14. Available: http://www.gni.com [Dec. 13, 2009].

[4] Peter Mell, Timothy Grance, "The NIST Definition of Cloud Computing", Recommendations of the National Institute of 
Standards and Technology, September 2011, Special Publication 800-145

[5] Arora Pankaj, Wadhawan C.Rubal, Er.Ahuja P.Satinder, 2012, "Cloud Computing Security Issue in Infrastructure as a Service", International Journal of Advance Research in Computer Science and Software Engineering.

[6] Habib, S. M., Hauke, S., \& Ries, S. (2012) "Trust as a facilitator in cloud computing: a survey", Journal of Cloud Computing, 01-18.

[7] Parsi, K., \& M.Laharika. (2013) "A Comparative Study of Different Deployment Models in a Cloud", International Journal of Advanced Research in Computer Science and Software Engineering , 3 (5), 512-515.

[8] http://www.ibm.com/developerworks/cloud/library/clcloudservie liaas/.

[9] http://www.statechmagazine.com/article/2014/03/5important-benefits-infrastructure-service.

[10] Kuyoro, S., Ibikunle, F., \& Awodele, O. (2011)"Cloud Computing Security Issue and Challenges", International Journal of Computer Networks, 3 (5), 247-255.

[11] Cloud Computing Bible, 2011, Wiley Publishing, Inc., Indianapolis, Indiana, pg. 8-9.

\section{AUTHORS PROFILE}

Kamalinder Kaur is working currently as Assistant Professor in Chandigarh Group of Colleges, Landran, Punjab, India. She has five years of teaching experience, her research interest includes Networking with specialization in Mobile Ad-hoc Network (MANET).

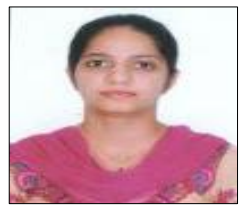

Nupur is working currently as Assistant Professor in Chandigarh Group of Colleges, Landran, Punjab, India. She has two years of teaching experience, her research interest includes Networking and Database Security.

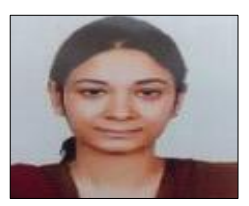

(C) 2016 by the author(s); licensee Empirical Research Press Ltd. United Kingdom. This is an open access article distributed under the terms and conditions of the Creative Commons by Attribution (CC-BY) license. (http://creativecommons.org/licenses/by/4.0/). 